October 2002 • NREL/SR-560-32733

\title{
Annual Technical Status Report of The Regulatory Assistance Project: September 2000- September 2001
}

The Regulatory Assistance Project Gardiner, Maine Montpelier, Vermont

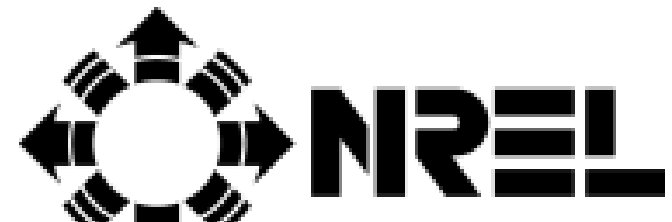

National Renewable Energy Laboratory

1617 Cole Boulevard Golden, Colorado 80401-3393

NREL is a U.S. Department of Energy Laboratory Operated by Midwest Research Institute $\bullet$ Battelle $\bullet$ Bechtel 


October $2002 \quad$ NREL/SR-560-32733
\[ \quad \text { Annual Technical Status Report } \]
of The Regulatory Assistance
Project: September 2000_
September 2001

The Regulatory Assistance Project

Gardiner, Maine

Montpelier, Vermont

NREL Technical Monitor: Thomas Basso

Prepared under Subcontract No. ADD-0-30605-03 


\section{NOTICE}

This report was prepared as an account of work sponsored by an agency of the United States government. Neither the United States government nor any agency thereof, nor any of their employees, makes any warranty, express or implied, or assumes any legal liability or responsibility for the accuracy, completeness, or usefulness of any information, apparatus, product, or process disclosed, or represents that its use would not infringe privately owned rights. Reference herein to any specific commercial product, process, or service by trade name, trademark, manufacturer, or otherwise does not necessarily constitute or imply its endorsement, recommendation, or favoring by the United States government or any agency thereof. The views and opinions of authors expressed herein do not necessarily state or reflect those of the United States government or any agency thereof.

Available electronically at http://www.osti.gov/bridge

Available for a processing fee to U.S. Department of Energy

and its contractors, in paper, from:

U.S. Department of Energy

Office of Scientific and Technical Information

P.O. Box 62

Oak Ridge, TN 37831-0062

phone: 865.576.8401

fax: 865.576.5728

email: reports@adonis.osti.gov

Available for sale to the public, in paper, from:

U.S. Department of Commerce

National Technical Information Service

5285 Port Royal Road

Springfield, VA 22161

phone: 800.553.6847

fax: 703.605.6900

email: orders@ntis.fedworld.gov

online ordering: http://www.ntis.gov/ordering.htm 


\section{Foreword}

This report discusses the work undertaken by the Regulatory Assistance Project (RAP) under subcontract to the National Renewable Energy Laboratory. The work is part of a larger U.S. Department of Energy effort to further the development and safe and reliable deployment of distributed resources within the nation's electricity system.

Distributed resources offer many economic and reliability benefits to customers, utilities, and society as a whole. But in some very important ways, our state regulatory practices inadvertently have made it difficult for these resources to be deployed. Understanding the existing regulatory barriers may lead to their removal. States such as Texas, New York, California, and others have already undertaken new regulatory approaches that simplify the technical integration of distributed resources into their local distribution networks. We encourage regulators and interested parties to become familiar with the work now under way in these states and to take steps to ease the integration of small-scale resources into local distribution systems. 


\section{Table of Contents}

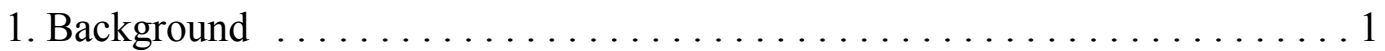

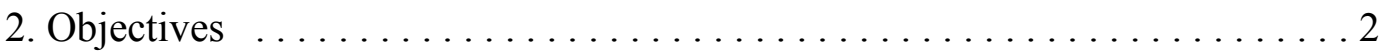

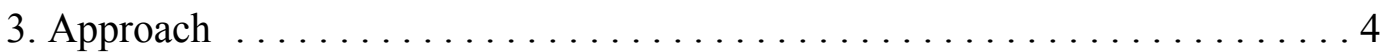

3.1. Task 1: Research, Analysis, and Development of Materials on Regulatory Policies for Distributed Resources . . . . . . . . 4

3.2. Task 2: Refinement of Materials on Institutional Barriers to Distributed Resources Posed by Utility Regulation . . . . . . . . . . 4

3.3. Task 3: Development of Requirements for a Draft Model Environmental Output Standard(s) for Small-Scale Generation . . . . 4

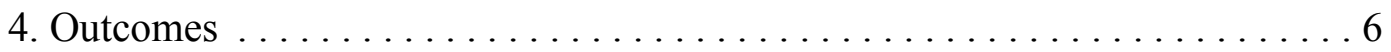

4.1. Task 1: Research, Analysis, and Development of Materials on Regulatory Policies for Distributed Resources . . . . . . . . . 6

4.1.1. Distribution System Cost Methodologies for Distributed Generation ................. 6

4.1.2. Distributed Resource Distribution Credit Pilot Programs - Revealing the Value to Consumers and Vendors ..................... 7

4.1.3. Distributed Resources and Electric System Reliability . . . 7

4.1.4. Accommodating Distributed Resources in Wholesale Markets .................. 8

4.2. Task 2: Refinement of Materials on Institutional Barriers to Distributed Resources Posed by Utility Regulation . . . . . . . . . 8

4.3. Task 3: Development of Requirements for a Draft Model

Environmental Output Standard(s) for Small-Scale Generation ... 9

4.3.1. Process ...................... 9

4.3.2. Working Draft Model Rule .............. 10 


\section{Background}

As the electric industry has restructured over the past several years, the interest in using costeffective distributed resources (DR) has begun to grow among some customers, utilities, and utility regulators. The development of small, modular generation technologies such as photovoltaics, micro-turbines, and fuel cells along with newer small-scale combustion technologies, all of which offer unprecedented opportunities for highly customized applications, have helped to stimulate this interest. Today, a variety of DR deployment choices exist on both the utility and the customer side of the electrical meter. From the customer point of view, DR offers increased reliability, a high degree of individual load-following capability, and lower costs for power and power delivery. For the distribution utility, strategic use of DR can defer or avoid larger capital investments in the distribution system as well as improve the quality of service to customers.

Utility regulatory practice, however, is not entirely friendly to the use of DR. More as an artifact of history than by intention, electricity utility regulation developed around an industry based on central-station generation and ownership of generation facilities by a single regulated monopoly. In general, most regulatory practice is designed to reward sales, and many costs are averaged across large numbers of customers when rates are established. Thus, the economic value of installing DR is often not apparent to the person or entity making the deployment decision. This is particularly true for DR deployed on the customer's side of the meter. In addition to the problem of current regulatory practice blocking the right decision maker from seeing the value of DR, the newly developed wholesale power markets have generally provided little opportunity for DR to participate in them. Thus, the economic value of DR deployment goes unrealized at both the retail and wholesale levels.

The task of addressing these regulatory barriers belongs to state and federal electricity regulators, but in many instances, the regulators are unaware of the problems or of the economic value of DR that is being lost to the system as a whole.

The work undertaken over the past year under contract to the National Renewable Energy Laboratory (NREL) by The Regulatory Assistance Project (RAP) has focused on identifying and removing the regulatory and institutional barriers that keep the full economic value of DR from being realized. The U.S. Department of Energy's Distributed Power Program (DPP) was initiated in January 1999 to address overall systems operation, reliability, safety, power quality, and institutional issues by focusing on three main R\&D activities: (1) strategic research, (2) system integration, and (3) institutional issues. RAP's work for NREL, as part of the overall initiative, focuses on institutional issues. 


\section{Objectives}

The objectives of RAP's work in this contract year were to develop regulatory policy options that would reduce the institutional and infrastructure barriers to full-value deployment of distributed power systems. There are several players in the electricity industry who could and should be able to realize the economic benefits of DR: customers, distribution utilities, DR vendors, wholesale market participants, and, of course, regulators. Because existing regulatory systems often do allow these benefits to be realized, many who could benefit from using DR are either unaware of those potential benefits or, worse, would actually experience economic penalty if DR were deployed. Policies are needed that can establish costs and price signals that will reveal the value of DR to the party most likely to deploy it. Regulation should provide the right incentives to reward the entity in the best position to deploy the DR. Finally, wholesale and retail market structures and rules must operate to allow DR to be a competitive choice.

Specifically, RAP's objectives in carrying out this work were:

1. To research and develop information, tools, and options for regulatory policies that would encourage the deployment of DR where cost-effective and environmentally beneficial

2. To implement the above information, tools, and proposed options along with additional related information to refine those and further establish both the means and the targeted draft proposals for removing or overcoming regulatory and institutional barriers to distributed power and energy efficiency resources

3. To establish and foster the adoption of a national model for output-based emissions performance standards for DR that could inform state utility and environmental regulator actions in each state.

These objectives were organized into three primary tasks:

- Task 1: Information and Tools for Establishing Options for, and for Consideration of (e.g., Evaluation of), Regulatory Policies for Distributed Resources Understanding existing policies and their consequences/impacts on DR implementation, identifying the major institutional and regulatory impediments to DR, and establishing options to eliminate or overcome them will be accelerated by researching that information and developing tools for consideration of new or revised policy alternatives.

- Task 2: Removing or Overcoming the Institutional Barriers to Distributed Resources Posed by Utility Regulation

State regulation of electric distribution systems will define the ground rules for the economic and technical opportunities for deployment of distributed power resources (including energy efficiency) on both the customer's and the utility's side of the electric meter. Examples include reforming regulation to: (1) make the deployment of DR consistent with 
the distribution company's own profit motive, (2) create distribution system rate designs that give customers more accurate price signals in high-cost geographical areas, such as through disaggregated distribution "credits" for those who install distributed resources, (3) encourage net metering, (4) make distribution company "IRP" obligations with effective performance-based regulatory approaches, and (5) create policies regarding the purchase of surplus energy, storage, and load balancing options.

\section{- Task 3: Environmental Output Standards for Small-Scale Generation}

Some environmental regulators had voiced concern regarding potential air emissions impacts of some DR, and some expressed an interest and willingness to work with state utility regulators on the issues of environmental impacts of DR. The mounting concern over air impacts of small-scale generation could be pursued head on by engaging state environmental regulators who support the DR vision. Most actions that utility regulators can take have environmental consequences, and much of what environmental regulators do has economic consequences for utilities. A better understanding of the ways in which their jurisdictions overlap will go a long way toward improving both the economic efficiency and environmental "footprint" of the nation's electricity sector. DR offer many benefits, including reliability enhancement, environmental protection, and cost savings, but some distributed generation technologies may have detrimental impacts on the environment, primarily in the form of airborne pollutants. The expected growth in the deployment of DR will pose new challenges for utility and environmental regulators as the identification and tracking of their environmental effects also grows in importance. 


\section{Approach}

\subsection{Task 1: Research, Analysis, and Development of Materials on Regulatory Policies for Distributed Resources}

Under this task, RAP performed research and analysis and wrote four reports for the utility regulatory community that discussed four key aspects of DR in a regulated environment. These were:

1. Simplified methods for analyzing distribution system costs

2. A system of deaveraged distribution credits for DR in high-cost areas

3. Case studies of reliability applications of DR

4. Approaches for accommodating DR in wholesale markets.

In performing this work, RAP solicited input and peer review from key stakeholders, including regulators, power marketers, customers, utility officials, and system operators. The results of these studies are available on RAP's Web site (www.raponline.org), and hard copies will be distributed in late 2001 to all state utility regulators, their senior electricity policy advisors, and a wide variety of interested parties. RAP has and will continue to present the findings of this research at a variety of workshops and meetings attended by the stakeholders (e.g., meetings of the proposed National Distributed Resources Coordinating Committee and NARUC).

\subsection{Task 2: Refinement of Materials on Institutional Barriers to Distributed Resources Posed by Utility Regulation}

This task had two objectives: to educate state regulators about the benefits of DR and to provide feedback to RAP by receiving stakeholder inputs and critically evaluating and refining the proposed DR barrier materials developed under Task 1 . This activity was primarily accomplished via two technical workshops: one for state utility regulators from Eastern states and one for Western state utility regulators. RAP prepared and presented these two-day technical workshops on removing or overcoming regulatory barriers to DR using materials developed by RAP and research developed by others. Materials used at the technical workshops included RAP's papers on Progress and Profits Through Distributed Resources, NARUC 2000, and white papers prepared for NARUC on rate design, a PBR for DR handbook, and system reliability opportunities for DR as well as the four studies developed in Task 1. RAP used the feedback from the participants at the technical workshops to refine the Task 1 research papers.

\subsection{Task 3: Development of Requirements for a Draft Model Environmental Output Standard(s) for Small-Scale Generation}

This task was to identify the issues and resources and develop the background, criteria, and requirements for developing draft emissions performance standards for DR. This information was used to prepare a Working Draft for Comment Model Emissions Rule for Distributed Resources. 
RAP formed a national working group of utility regulators, environmental regulators, power marketers, and other key stakeholders that met periodically and through regular conference calls to share information and research and to develop, discuss, and exchange draft model criteria for regulating the air emissions of distributed generation. 


\section{Outcomes}

\subsection{Task 1: Research, Analysis, and Development of Materials on Regulatory Policies for Distributed Resources}

RAP researched, analyzed, and prepared four reports for the regulatory community on the "how to" of removing regulatory barriers. Initial drafts were posted for comment on RAP's Web site with notice sent to a wide list of parties interested in DR. The drafts were distributed at regional workshops and other RAP workshops, and final reports were based on all comments. The reports have been finalized, and hard copies were distributed to many electricity regulatory commissioners and to many other interested parties. The content of the reports is described below. The reports may be found at http://www.nrel.gov/publications.

\subsubsection{Distribution System Cost Methodologies for Distributed Generation}

This study analyzed the distribution system cost data filed by 124 investor-owned utilities on their required FERC Form 1 filings for the years 1994-1999. The costs analyzed were the embedded and marginal costs for distribution plant lines and feeders, both plant investment and operation and maintenance expense, and for transformers and substations, both plant investment and operation and maintenance expense.

The study found that, on average, marginal costs are 2.4 times embedded average costs. Incremental spending on distribution system raises rates, with an average aggregate revenue requirement impact across the utilities studied of $\$ 1.2$ billion every year.

The average investment in lines and feeders was greater than $\$ 5.6$ billion. For transformers and substations, it exceeded $\$ 800$ million. However, the costs in both categories are highly dependent on geographic location. There are high-cost utilities and lower-cost utilities, and there are highcost areas and low-cost areas within each utility. This data shows that there is considerable economic opportunity for deploying DR within the distribution system, particularly to reduce line and feeder costs.

The study concludes that state utility regulation should require regular filings of distribution system investment and O\&M plans that require a trade-off analysis of potential DR applications to identify those areas where DR would lower marginal cost.

\subsubsection{Distributed Resource Distribution Credit Pilot Programs - Revealing the Value to Consumers and Vendors}

This study analyzed methods to create a price signal for individual customers that would encourage the deployment of DR where cost-effective. Regulatory practice has long averaged distribution costs across all customers and created rates that spread these costs on an average cost basis. This practice encourages the socially desirable goal of universal electric service and for this reason is unlikely to be changed. Nevertheless, distribution costs do vary greatly across utility service territories, ranging from $0 \notin / \mathrm{kWh}$ to $20 \notin / \mathrm{kWh}$. The high-cost areas can be either urban or rural. Commonly, about $5 \%$ of a typical distribution system is "high cost" at any one time. 
The study suggests that a system of distribution credits could send the right price signal to individual customers, thus encouraging customer investment in DR without upsetting the current over-all averaged pricing practice. The credits could be limited to environmentally desirable DR resources and could use either a standard payment approach or require competitive bidding among customers. The size and time duration of the credits should be shaped to match the pattern of costs otherwise likely to be incurred by the utility to upgrade and/or maintain its system.

The study concludes that pilot DR rate credit programs should be undertaken by states and distribution utilities to see how best to design larger programs. A number of helpful design criteria are offered in the study.

\subsubsection{Distributed Resources and Electric System Reliability}

The reliability contributions of DR must be considered from at least three points of view:

- The individual customers

- Groups of customers and their local distribution companies

- Wholesale market managers, reliability managers, and system operators.

This report examines case studies in which DR have been considered or have been deployed to address the reliability objectives of one or more of those responsible parties.

DR may be tapped to address reliability challenges in several ways:

\section{- Improving power quality and ensuring uninterrupted power to individual} customers

DR can improve power quality in stressed service areas, at the end of long distribution lines, and in customer locations where especially high quality power is needed and can provide on-site generation capability under the control of customers who demand uninterrupted service.

- Relieving distribution overloads and transmission congestion

DR can lighten the load on stressed distribution systems and can relieve congestion on transmission systems, lowering the costs of serving load pockets and improving the resilience of transmission systems.

- Meeting generation adequacy requirements

DR can lower system requirements on a "baseload" basis and can meet or shave peak loads so as to satisfy essential reserve margin requirements and avoid overloads and involuntary load-shedding.

- Providing ancillary services to the system

DR can provide an array of ancillary services to system operators and reliability managers.

The case studies discussed in the report illustrate DR applications in each of these categories. 


\subsubsection{Accommodating Distributed Resources in Wholesale Markets}

This report describes the key set of policies needed to allow DR to freely participate in all available wholesale markets. They are not technology-prescriptive - they do not ordain winners and losers - but instead aim to give incentives to market participants to develop innovative, more reliable, and less risky methods of meeting the nation's demand for electricity. These policies include the following:

- Demand-side bidding and multi-settlements

- Demand response (participation of load management in spot markets)

- Opening the ancillary services market to DR

- Resource aggregation and management

- Increasing market liquidity

- More economically efficient transmission and distribution rate design

- Public benefits programs, including funding mechanisms, in support of investment in long-term end-use energy efficiency.

Viewed another way, these policies identify market, rather than engineering, mechanisms that can expose the value of distributed resources. Once these values are uncovered, regulators can leave it to the many thousands of dedicated and creative people around the world to find the best ways of capturing that value.

\subsection{Task 2: Refinement of Materials on Institutional Barriers to Distributed Resources Posed by Utility Regulation}

The Western States Workshop occurred in Salt Lake City, Utah, on May 2-3, 2001, and the Eastern States Workshop was held in Philadelphia, Pennsylvania, on May 9-10, 2001. Despite the difficultly of drawing a full audience for these technical workshops, both proved to be successful, with engaged participants who gave RAP high marks both for content and relevance. The difficulty in attracting an audience is indicative of problems DR faces among the state regulatory community: a general lack of DR awareness and strong competition for regulatory attention. The restructuring of the electric industry, especially the push to establish workably competitive wholesale markets, has absorbed much of the time and resources of state regulators, and DR issues are often not viewed as immediately critical. Nevertheless, the two workshops were each attended by about eight participants - a blend of state utility regulators, state consumer advocates, and energy office representatives - and the discussions showed that once regulator attention is focused on DR issues, there is high interest in the greater use of costeffective DR in both the Western and Eastern states. The immediate interest in DR is probably higher in the Western states because of the high market clearing prices experienced in the California market through much of 2001.

The research and analysis RAP developed pursuant to Task 1 was well-received and formed the basis for the workshop discussions. It is our impression that the issues discussed in the papers contained new ideas for most of the attendees. The workshops revealed a clear need for further educational initiatives directed to state regulators as well as a need for direct assistance in 
improving ISO operating rules to better allow DR to realize their full economic value. Several states in the Eastern workshop expressed an interest in having follow-up workshops in their own states or ISO regions.

\subsection{Task 3: Development of Requirements for a Draft Model Environmental Output Standard(s) for Small-Scale Generation}

\subsubsection{Process}

The Regulatory Assistance Project convened a group of approximately 30 professionals consisting of state utility regulators, state air pollution regulators, representatives of the DR industry, environmental advocates, and federal officials. This group participated in an effort to develop model emissions standards for smaller-scale, primarily distributed, electric generation technologies. Most of the effort was conducted through e-mail, list-serve, and telephone conference calls, and there were two face-to-face meetings of the group during 2001.

The electric industry has major effects on our local, regional, and global environments. Increased competition in the electric industry can bring new environmental problems as well as new opportunities for improvement. There have been significant developments in small-scale generation technologies. The growing availability of cost-effective distributed generation micro-turbines, diesel "gen-sets," fuel cells, solar panels, natural gas-fired systems, etc. — is changing the nature of the electric network. Although the potential electric benefits of such technologies (improved reliability, lower costs, and so on) are becoming increasingly well understood, their environmental impacts, and benefits, may be less so. The object of this group was to develop a set of model rules that states can adopt in whole or adapt that will foster the deployment of environmentally sustainable and economically efficient distributed generation.

RAP enlisted Nancy Seidman of the Massachusetts Department of Environmental Protection and Christopher James of the Connecticut Department of Environmental Protection to act as cocoordinators of the project. After consulting with utility regulators, environmental regulators, industry representatives, and other interested persons, a list of potential members of the working group was put together and, in the fall of 2000, letters of invitation were sent to them. The work began in earnest in January 2001 with a "kick-off" conference call and, at the end of the month in Chicago, our first in-person meeting.

The first meeting was dedicated primarily to developing a set of objectives and principles to guide the work and a time line in which to finish it. The group discussed a series of questions:

I. What do we hope to accomplish?

II. What is the purpose of the rule?

III. What is its scope?

IV. What constraints do we face?

V. What approach to emissions regulation should we take?

A Statement of Objectives, General Principles, and Scope emerged over the following months. 
The working group organized several sub-groups to address specific issues, including: applicability, emissions, manufacturer certification, and offsets (credits for combined heat and power, etc.). The sub-groups developed information and suggested approaches for tackling certain issues. The applicability sub-group considered the scope of the rule. How would the rule's applicability be defined — by generating capacity, output, technology, purpose for generation (i.e., emergency, peaking, baseload), or location (attainment or non-attainment area)? The emissions sub-group put together a comprehensive spreadsheet detailing the emissions performance of current distributed generating technologies - that is to say, the state-of-the-art for technologies that are now, or will very shortly be, available in the market. The certification sub-group studied how other manufacturer certification programs currently work (for example, the US EPA's ENERGY STAR program for appliances and its off-road mobile engine program). The offsets sub-group considered methods for calculating the net emissions reductions resulting from combined heat and power (CHP) installations and administratively streamlined and reliable ways to credit such installations with those savings.

The sub-groups reported regularly on their progress to the working group. By spring, the work had advanced to warrant a second in-person meeting. This meeting was convened to discuss central, interrelated substantive issues: applicability and emissions standards. Proposals that had been developed by various members of the working group formed points of departure for the discussion. The meeting revealed areas of consensus and disagreement, and an action plan for resolving outstanding issues was set out.

Discussions continued among various members of the working group, and around those discussions an ad hoc drafting committee formed. Several drafts of the rule circulated among the ad hoc committee during the summer of 2001, so that by September a draft could be forwarded to the working group as a whole for its consideration. Nothing in the draft represents a final agreement of the ad hoc drafting committee or of the working group. Though reflective of the general directions taken by the working group, it is a discussion draft only.

\subsubsection{Working Draft Model Rule}

A Working Draft Model Rule for Comment has been prepared, and comments from all members of the working group and other interested parties have been solicited. The Working Draft Model Rule and technical support documents can be found at http://www.rapmaine.org/distribution.html.

The Working Draft Model Rule undertakes to establish emissions standards for all non-mobile electric generating resources that are not otherwise covered under existing federal Clean Air Act requirements. The standards will cover four types of emissions: nitrogen oxide (NOx), particulate matter - 10 microns (PM10), carbon monoxide (CO), and carbon dioxide (CO2). The rule distinguishes between resources that are local in Clean Air attainment areas and those that are in non-attainment areas. At present, the draft-recommended standards are to be decided. 
The Working Draft Model Rule distinguishes between three types of generator use based on annual hours of operation: emergency, fewer than 300 hours; peaking, fewer than 700 hours; and baseload, 700 or more hours. The general operation of the model rule establishes cleaner emission standards from units that run more frequently and cleaner standards for non-attainment areas. Credits are established for CHP applications, reduction of flared gases, and efficiency investments that offset emissions. Standards for record keeping are also established.

Future RAP contract activities call for further public review of the working draft model rule. Then, the objective is to establish a final draft model rule for states' consideration, adaptation, and adoption under their regulatory purview. 


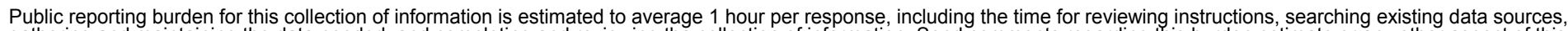

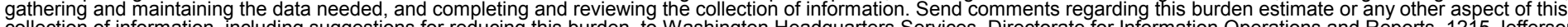
Davis Highway, Suite 1204, Arlington, VA 22202-4302, and to the Office of Management and Budget, Paperwork Reduction Project (0704-0188), Washington, DC 20503.
1. AGENCY USE ONLY (Leave blank)
2. REPORT DATE
October 2002
3. REPORT TYPE AND DATES COVERED
Subcontract Report: September 2000-September 2001

4. TITLE AND SUBTITLE

Annual Technical Status Report of the Regulatory Assistance Project: September 2000September 2001

5. FUNDING NUMBERS

CF: ADD-0-30605-03

TA: DP02.1001

6. $\operatorname{AUTHOR}(\mathrm{S})$

The Regulatory Assistance Project

7. PERFORMING ORGANIZATION NAME(S) AND ADDRESS(ES)

The Regulatory Assistance Project

177 Water Street

50 State Street

Gardiner, Maine 04345

Montpelier, Vermont 05602

207-582-1135 802-223-8199

9. SPONSORING/MONITORING AGENCY NAME(S) AND ADDRESS(ES)

National Renewable Energy Laboratory

1617 Cole Blvd.

Golden, CO 80401-3393

8. PERFORMING ORGANIZATION REPORT NUMBER

11. SUPPLEMENTARY NOTES

NREL Technical Monitor: Thomas Basso

12a. DISTRIBUTION/AVAILABILITY STATEMENT

National Technical Information Service

12b. DISTRIBUTION CODE

U.S. Department of Commerce

5285 Port Royal Road

Springfield, VA 22161

1. ABSTRACT (Maximum 200 words)

This report summarizes the work in 2001 by the Regulatory Assistance Project (RAP), under contract to the National

Renewable Energy Laboratory. This work focused on identifying and removing the regulatory and institutional barriers that keep the full economic value of distributed resources from being realized.

The following five reports present the work details:

- Accommodating Distributed Resources in Wholesale Markets, NREL/SR-560-32497

- Distributed Resource Distribution Credit Pilot Programs - Revealing the Value to Consumers and Vendors, NREL/SR-560-32499

- $\quad$ Distributed Resources and Electric System Reliability, NREL/SR-560-32498

- Distribution System Cost Methodologies for Distributed Generation, NREL/SR-560-32500

- Distribution System Cost Methodologies for Distributed Generation Appendices, NREL/SR-560-32501

Visit www.eren.doe.gov/distributedpower for more information about RAP contract activity to establish environmental output air emissions standards for small-scale electricity generation (to be published as a future NREL subcontract report).

14. SUBJECT TERMS

The Regulatory Assistance Project; subcontract; distributed energy resources; DER, $\mathrm{DR}$, distributed power; utility grid; air emissions; public utility commission; regulatory policy; restructuring; barriers; National Renewable Energy Laboratory; NREL

17. SECURITY CLASSIFICATION OF REPORT Unclassified
18. SECURITY CLASSIFICATION OF THIS PAGE Unclassified
19. SECURITY CLASSIFICATION OF ABSTRACT Unclassified
15. NUMBER OF PAGES

16. PRICE CODE

20. LIMITATION OF ABSTRACT

UL 